\title{
Prevalence of Salmonella Infection in Intensive Poultry Farms in Hawassa and Isolation of Salmo- nella species from sick and dead chickens
}

\author{
Kassaye Aragaw ${ }^{1 *}$, Lencho Terefe ${ }^{2}$ and Mesele Abera ${ }^{1}$ \\ ${ }^{1}$ Hawassa University, Faculty of Veterinary Medicine, P.O. Box 05, Hawassa, Ethiopia ${ }^{2}$ Mekele \\ University, Faculty of Veterinary Medicine, P.O. Box 231, Mekele, Ethiopia \\ *Corresponding author: kassaye33@yahoo.com
}

\section{Abstract}

A bacteriological study of Salmonella Gallinarum/Pullorum was conducted in intensively managed chickens in Hawassa, Ethiopia between November 2008 and May 2009. The objectives of the study were to estimate the bacteriological prevalence of S. Gallinarum/Pullorum in apparently healthy chickens and to assess the proportional morbidity/mortality from S. Gallinarum/Pullorum in sick/dead chickens. Cloacal swabs were collected from a total of 380 randomly selected chickens from 3 poultry farms to estimate the prevalence, whereas necropsy samples of liver, spleen and ceca were collected from 31 sick/dead chickens to estimate the proportional morbidity/mortality. The prevalence of Salmonella infection (S. Gallinaum/Pullorum) was $0.8 \%$ (3/380), while isolation was possible from $16.1 \%(5 / 31)$ sick/dead chickens. Only S. Gallinarum was isolated from cloacal swabs. Of the 6 isolates obtained from necropsy samples 1 was $\mathrm{S}$. Pullorum and the rest $5 \mathrm{~S}$. Gallinarum; and, 3 were from liver, 2 from cecum and 1 from spleen. It is concluded that salmonellosis is prevalent and fowl typhoid and pullorum disease have significant role in morbidity and mortality of intensively managed chickens in Hawassa. This result may indicate the challenge that the poultry industry of the country may face from S. Gallinarum/Pullorum in the future in its intensification. Concerted efforts, therefore, should be made at national and local levels to control the diseases.

Keywords · Ethiopia · Hawassa · Isolation · Prevalence · Salmonella Gallinarum-Pullorum

\section{Introduction}

Ethiopia owns $42,915,629$ poultry, of which $95.37 \%$ is under rural holdings while the rest $4.63 \%$ is urban. About $98 \%$ of the total national poultry population consists of indigenous chickens and the remaining $2 \%$ consists of exotic breeds (CACC, 2003). Virtually all poultry under rural holdings in this country is free ranging. 
The country needs to increase the number of its poultry and intensify its management in order to satisfy the protein need of its ever increasing human population estimated at 79,086,894 in 2007 (World Bank, 2008). However poultry population in Ethiopia is not growing, it is even under a gradual decline (FAO, 2007) and is highly constrained by diseases among other factors. The current rates of mortality due to diseases from day old to adult chicken are estimated to be 20 to $50 \%$ in Ethiopia (Tadele Dessie and Yilma Jobre, 2004). Among diseases, fowl typhoid and pullorum disease are expected to incur heavy losses to the poultry industry as it is the case in other African countries (Bell et al., 1990; Bouzoubaa et al., 1992; Chrysostome et al., 1995; Sato et al., 1997). Fowl typhoid in chickens is caused by Salmonella Gallinarum and is more often observed in the later growing period and in mature stock. The clinical signs resemble those of septicemia, with inappetance and, eventually, death. Pullorum disease, on the other hand, is caused by S. Pullorum and, in its acute form, is almost exclusively a disease of young chickens. Confirmatory diagnosis depends on the isolation of the organism while serological tests are satisfactory for establishing the presence and estimating the prevalence of infection within a flock (OIE, 2008).

Serological and bacteriological reports confirmed the presence of S. Gallinarum/Pullorum in chickens in Ethiopia (Pegram et al., 1981; Melese G/Tsadik, 1991, unpublished; Assefa Wakwoya, 1992, unpublished; Molomo, 1998, unpublished; Getnet Abie et al., 2003). As the poultry industry develops and become more intensified, the incidence of salmonellosis including pullorum disease and fowl typhoid may become greater as it was in the United States and Canada during the time of intensification (Snoeyenbos, 1978). Pullorum disease and fowl typhoid are economically important diseases, with out their effective control through organized national regulatory programs; the profitable production of poultry would be impossible (Williams, 1978). Ethiopia currently has no national regulatory program for these diseases. Although there is some information concerning the presence of the causative agent and the diseases in Ethiopia, there is lack of information with regard to distribution, social and economic impacts analysis of the disease in the country in general. Knowledge of the prevalence of the disease with confirmatory diagnosis is of paramount importance to embark on a control or prevention program as clinical signs, post-mortem findings and flock history are of limited value in arriving at a diagnosis because of the similarity of the diseases to a number of other diseases (Snoeyenbos, 1978). Therefore this study was conducted to estimate the prevalence of S. Gallinarum/Pullorum in apparently healthy chickens and 
to measure the relative importance of fowl typhoid and pullorum disease in morbidity/ mortality of intensively managed chickens in Hawassa.

\section{Materials and Methods}

Study area

The study was conducted in poultry farms in Hawassa, Southern Ethiopia, located $275 \mathrm{~km}$ south of Addis Ababa, from November 2008 to May 2009. The annual rainfall and temperature of the area varies from $800-1000 \mathrm{~mm}$ and $20.1-25^{\circ} \mathrm{C}$ respectively (CAA, 2004). The study involved 4 poultry farms: Hawassa Poultry Multiplication and Breeding Center (HPMBC), SOS poultry farm (SOS), poultry farm of Awassa College of Agriculture (ACA) and a private poultry farm at the outskirt of Hawassa at Dato (Dato). The farms included in our study were the major poultry farms in Hawassa at the time of this study.

Study animals and management

The study involved collection of cloacal swab samples from 380 chickens aged between 6 weeks and 12 months and necropsy samples from 31 recently deceased or sick chickens aged 1 week to 12 months. The study chickens were all exotic breeds kept mainly for table egg production except for HPMBC which distributes pullets, cockerels and day old chicks for farmers. Chickens in the farms were kept over deep litter except for SOS where some of the chickens were kept in cages. The description of the study chickens is summarized in Tables 1 and 2.

\section{Sample collection}

Cloacal swab samples of chickens from HPMBC, ACA and SOS were tested for S. Gallinarum/Pullorum while recently dead or sick chickens from HPMBC, SOS and Dato were autopsied to collect samples for culture.

Samples were collected according to the recommendations of the OIE (2008). Cloacal swab samples for bacteriological-prevalence were collected from live birds using sterile cotton tipped swabs moistened with buffered peptone water (AES, Combourg, France). The swabs were kept in properly plugged sterile test tubes and transported as soon as possible on ice to the laboratory where they were inoculated immediately on appropriate culture media.

Postmortem examinations were performed on dead and sick chickens kindly provided by the farms. The surfaces of liver and spleen obtained during post- 
mortem were decontaminated by searing with hot spatula before they were cut with sterile scalpel blade for collection of samples from their interior using sterile cotton tipped swabs. The ceca were cut with sterile blade and the internal wall was sampled on sterile cotton tipped swabs.

Isolation and identification

Isolation and identification was done according to Quinn et al. (1999) and OIE (2008). The cloacal and cecal swabs were directly plated on xylose lysine desoxycholate (XLD) agar (Oxoid, Basingstoke, England) and the plates were incubated at $37^{\circ} \mathrm{C}$ for 24 to 72 hours. Swabs from liver and spleen were streaked on blood agar (Green Star Impex Pvt. Ltd., Secunderabad, India) and XLD agar and incubated at $37^{\circ} \mathrm{C}$ for 24 and up to 72 hours respectively. Presumptive colonies (red colonies with or without black center on XLD agar) were subcultured on XLD agar for isolation of pure cultures. The pure cultures were streaked on brain heart infusion (BHI) agar $(\mathrm{CDH}$, India) slants for storage and further biochemical characterization.

The isolates were examined for motility, $\mathrm{H}_{2} \mathrm{~S}$ and indole production using sulphide indole and motility (SIM) medium (Oxoid, Basingstoke, England) and for lysine decarboxylation and $\mathrm{H}_{2} \mathrm{~S}$ production using lysine iron agar (LIA) (Oxoid, Basingstoke, England). They were also inoculated on triple sugar iron (TSI) agar (HiMedia, Mumbai, India) slant for lactose, sucrose and glucose fermentation, $\mathrm{H}_{2} \mathrm{~S}$ and gas production. Non-lactose fermenting, non-motile, indole negative isolates, decarboxylating lysine and producing $\mathrm{H}_{2} \mathrm{~S}$ were further characterized using Analytical Profile Index (API) 20E test kit (Biomerieux, France) and dulcitol fermentation test. Isolates typical of Salmonella not fermenting dulcitol and decarboxylating ornithine were considered S. Pullorum (Snoeyenbos, 1991; Pomeroy and Nagaraja, 1991; OIE, 2008).

Table 1: Description of chickens used for cloacal swab study

\begin{tabular}{lccll}
\hline Farm & Number of observations & Age in months & Management & Purpose \\
\hline ACA & 40 & 2 & Deep litter & $\begin{array}{l}\text { Egg production } \\
\text { Distribution to } \\
\text { farmers }\end{array}$ \\
HPMBC & 207 & 1.5 to 2 & Deep litter & Dag production \\
SOS & 133 & 12 & Deep litter + Cage & Egg \\
Total & 380 & & & \\
\hline
\end{tabular}


Table 2: Description of chickens used for necropsy study

\begin{tabular}{lccll}
\hline Farm & Number of observations & Age in months & Management & Purpose \\
\hline Dato & 10 & 12 & Deep litter & Egg production \\
HPMBC & 20 & $<1$ & Deep litter & $\begin{array}{l}\text { Distribution to } \\
\text { farmers }\end{array}$ \\
SOS & 1 & 12 & Deep litter + Cage & Egg production \\
Total & 31 & & & \\
\hline
\end{tabular}

\section{Results}

Cloacal swabs

Three of $380(0.8 \%)$ cloacal swab samples collected from the 3 farms were positive for S. Gallinarum (Table 3). Salmonella was isolated from only 1 of the 3 farms (SOS) investigated through cloacal swab samples. Of the 133 cloacal swab samples collected from this farm $3(2.3 \%)$ were positive and all of the isolates were of the biotype $\mathrm{S}$. Gallinarum. All the 3 birds tested positive were one year old layers.

\section{Postmortem samples}

Of 31 chicken undergone necropsy 5 (16.1\%) were positive for S. Gallinarum/ Pullorum (Table 4). A total of 6 samples collected from 5 birds were positive as the bacteria were isolated from both liver and cecum in one of the chickens. Four (12.9\%) and 1 (3.2\%) of 31 sick/dead birds examined had S. Gallinarum and S. Pullorum respectively. Five of the 6 isolates recovered were S. Gallinarum while the rest 1 was S. Pullorum. Of the recovered 6 isolates, $3(50 \%)$ were from liver, 2 (33.3\%) from cecum and 1 (16. 7\%) from spleen. Salmonella Gallinarum was isolated from all the organs tested (liver, spleen and cecum) while the only isolate of $\mathrm{S}$. Pullorum was recovered from liver. Salmonella Gallinarum/Pullorum was isolated from dead chickens originated from 2 of the 3 farms investigated in the autopsy study. Four of $20(20 \%)$ sick/dead birds from one of the farms (HPMBC) were positive for S. Pullorum/Gallinarum, while 1 out of 10 chickens (10\%) was positive in the other farm (Dato). The only chicken examined from SOS farm was negative. Interestingly, 207 cloacal swab samples from HPMBC were negative while S. Gallinarum/Pullorum was isolated from $20 \%$ of sick/dead chicken from the same farm.

Salmonella Pullorum was isolated from a 7 day old chick, while S. Gallinarum was isolated from three 7 day old chicks and 1 a year old chicken. 
Table 3: Number and percentage of chicken tested culture positive for S. Gallinarum/ Pullorum for cloacal swab samples

\begin{tabular}{lllll}
\hline Farm & Number of observations & Positive (\%) & Age in months & Biotype \\
\hline ACA & 40 & $0(0)$ & 2 & \\
HPMBC & 207 & $0(0)$ & 1.5 to 2 & \\
SOS & 133 & $3(2.26)$ & 12 & S. Gallinarum \\
Total & 380 & $3(0.79)$ & & \\
\hline
\end{tabular}

Table 4: Number and percentage of sick/dead chicken culture positive for S. Gallinarum/Pullorum from intensive farms in Hawassa

\begin{tabular}{llllll}
\hline Farm & $\begin{array}{l}\text { Number of } \\
\text { observations }\end{array}$ & Positive (\%) & Age in months & Biotype & Organ \\
\hline Dato & 10 & $1(10)$ & 12 & S. Gallinarum & Liver, cecum \\
HPMBC & 20 & $4(20)$ & $<1$ & $\begin{array}{l}\text { S. Gallinarum, S. } \\
\text { Pullorum }\end{array}$ & $\begin{array}{l}\text { Liver, cecum, } \\
\text { spleen }\end{array}$ \\
SOS & 1 & $0(0)$ & 12 & \\
Total & 31 & $5(16.13)$ & & & \\
\hline
\end{tabular}

\section{Discussion}

Cloacal swabs

The prevalence of S. Gallinarum/Pullorum infection (0.8\%) detected through cloacal swab samples in our study was lower than reports of Mdegela et al. (2000) from Tanzania and Islam et al. (2006) from Bangladesh who used the same sampling technique. The difference in the prevalence might partly be due to use of direct plating in the present study compared to enrichment in the others. Moreover, S. Pullorum and Gallinarum are not excreted extensively in the feces (Berchieri et al., 1995; Proux et al., 2002).

Postmortem samples

There is shortage of published information regarding cultural prevalence of S. Gallinarum/Pullorum in Ethiopia for comparison with our results. Getnet Abie et al. (2003) reported up to $97 \%$ mortality due to fowl typhoid which they confirmed by isolation in an outbreak in a farm in south western Ethiopia. There are some seroprevalence reports however. Assefa Wakwoya (1992, unpublished) reported a seroprevalence of $22.6 \%$ for chicken kept in small-scale farms in Addis Ababa, while seroprevalence of 10.4 - 28.3\% has been reported for large scale commercial farms in Addis Ababa and Debre Zeit (Melese G/ Tsadik, 1991, unpublished). The $16.1 \%$ prevalence of S. Gallinarum/Pullorum 
in sick /dead chicken recorded in the present study is lower compared to some literature reports from dead chicken in Bangladesh (Rahman and Samad, 2003; Rahman et al., 2004; Haider et al., 2004; Hossain and Islam, 2004). However it is high compared to other reports from the same country (Hossain et al., 2006; Akter et al., 2007). The failure of cloacal swab samples to detect presence of the agents in the farm where 4 of $20(20 \%)$ sick/dead chicken were affected (Tables 1 and 2) with them might partly be due to direct plating of the samples on selective media which might have reduced sensitivity of the test.

The isolation of S. Gallinarum and S. Pullorum in this study from cloacal swab samples and sick/dead birds indicates the existence of fowl typhoid and pullorum disease in intensive poultry farms in Hawassa. The existence of both diseases in HPMBC which distributes chicken to farmers throughout the southern region of Ethiopia is of great concern as the diseases have the potential for horizontal and vertical transmission (Snoeyenbos, 1991; Pomeroy and Nagaraja, 1991). The $16.1 \%$ prevalence of S. Gallinarum/Pullorum in sick/dead chicken recorded in the present study shows the significance of fowl typhoid/ pullorum disease in morbidity and mortality of chickens in intensive poultry farms in Hawassa; although more than one pathogens can be isolated from dead chicken (Rahman and Samad, 2003). The prevalence might have gone even higher if enrichment media was used. The result of this study may indicate the challenge, intensification of poultry production may face in the future in the country from fowl typhoid and pullorum disease unless due attention is given to the prevention and control of these diseases. Therefore concerted efforts such as organized national regulatory programs should be established to mitigate the losses and control the diseases.

\section{Acknowledgements}

We are grateful to the owners and managers of the farms for allowing us to use their chickens for the study and kindly providing us with sick/dead chicken.

\section{References}

Abie, G., Eguale, T., Ademe, M. and Abditcho, S., 2003. Fowl typhoid: A repeated attack in Jimma agricultural college poultry farm. In: Proceedings of the $17^{\text {th }}$ Annual Conference of the Ethiopian Veterinary Association (EVA), held in Addis Ababa, Ethiopia, June 5-6, 2003. pp. 101-107. 
Akter, M.R., Choudhury, K.A., Rahman, M.M. and Islam, M.S., 2007. Seroprevalence of salmonellosis in layer chickens with isolation, identification and antibiogram study of their causal agents. Bangl. J. Vet. Med., 5, 39-42.

Bell, J.G., Kane, M. and Lejan, C., 1990. An investigation of the disease status of village poultry in Mauritania. Prev. Vet. Med., 8, 291-294.

Berchieri, A. Jr., Iba, A.M. and Barrow, P.A., 1995. Examination by ELISA of sera obtained from chicken breeder and layer flocks showing evidence of fowl typhoid or pullorum disease. Avian Pathol., 24, 411-420.

Bouzoubaa, K., Lemainguer, K. and Bell, J. G., 1992. Village chickens as a reservoir of Salmonella Pullorum and Salmonella Gallinarum in Morocco. Prev. Vet. Med., 12, 95-100.

CAA, 2004. City Administration of Awassa (CAA): Project proposal on the poverty alleviation through micro financing, Awassa, Southern Nations Nationalities and Peoples Region, Ethiopia.

CACC, 2003. Statistical report on farm management practices, livestock and farm implements. Part II. Federal Democratic Republic of Ethiopia, Central Agricultural Census Commission (CACC), Ethiopian agricultural sample enumeration, 2001/02 (1994 E.C.).

Chrysostome, C.A.A.M., Bell, J.G., Demey F. and Verhulst, A., 1995. Sero prevalences to three diseases in village chickens in Benin. Prev. Vet. Med., 22, 257-261.

Dessie, T. and Jobre, Y., 2004. A review of the importance and control of Newcastle disease in Ethiopia. Ethiop. Vet. J., 8, 71-81.

FAO, 2007. Poultry sector country review-Ethiopia. FAO animal production and health division, emergency centre for transboundary animal diseases, socio economics, production and biodiversity unit, $\mathrm{p} 3$.

Haider, M.G., Hossain, M.G., Hossain, M.S., Chowdhury, E.H., Das, P.M. and Hossain, M.M., 2004. Isolation and characterization of Enterobacteria associated with health and disease in Sonali chickens. Bangl. J. Vet. Med., 2, 15-21.

Hossain, M.A. and Islam, M.A., 2004. Seroprevalence and mortality in chickens caused by pullorum disease and fowl typhoid in certain government poultry farms in Bangladesh. Bangl. J. Vet. Med., 2, 103-106. 
Hossain, M.S., Chowdhury, E.H., Islam, M.M., Haider, M.G. and Hossain, M.M., 2006. Avian Salmonella infection: Isolation and identification of organisms and histopathological study. Bangl. J. Vet. Med., 4, 07-12.

Islam, M.M., Haider, M.G., Chowdhury, E.H., Kamruzzaman, M. and Hossain, M.M., 2006. Seroprevalence and pathological study of Salmonella infections in layer chickens and isolation and identification of causal agents. Bangl. J. Vet. Med., 4, 79-85.

Mdegela, R.H., Yongolo, M.G.S., Minga, U.M. and Olsen, J.E., 2000. Molecular epidemiology of Salmonella gallinarum in chickens in Tanzania. Avian Pathol., 29, 457-463.

OIE, 2008. Fowl typhoid and pullorum disease. In: Terrestrial Manual. Office International des Epizooties (OIE), Paris, France. pp. 538-548.

Pegram, R.G., Ropeder, P.L., Hall, M.L.M. and Rowe, B., 1981. Salmonella in livestock and animal by-products in Ethiopia. Trop. Anim. Health Prod., 13, 203-207.

Pomeroy, B.S. and Nagaraja, K.V., 1991. Fowl typhoid. In: Calnek, B.W., Barnes, H.J., Beard, C.W., Reid, W.M. and Yoder, H.W., Jr. (Eds): Diseases of Poultry $9^{\text {th }}$ edn. lowa State University Press, Ames, pp. 87-99.

Proux, K., Humbert, F., Jouy, E., Houdayer, C., Lalande, F., Oger, A. and Salvat, G., 2002. Improvements required for the detection of Salmonella Pullorum and Gallinarum. Can. J. Vet. Res., 66, 151-157.

Quinn, P.J., Carter, M.E., Markey, B. and Carter, G.R., 1999. Clinical Veterinary Microbiology. Mosby International Limited, pp. 226-234.

Rahman, M.A. and Samad, M.A., 2003. Pattern of occurrence of single and concurrent diseases associated with mortality in commercial chickens in Bangladesh. Bangl. J. Vet. Med., 1, 15-20.

Rahman, M.A., Samad, M.A., Rahman, M.B. and Kabir, S.M.L., 2004. Bacterio-pathological studies on salmonellosis, colibacillosis and pasteurellosis in natural and experimental infections in chickens. Bangl. J. Vet. Med., 2, 01-08.

Sato, Y., Sato, G., Tuchili, L., Pandey, G.S., Nakajima, A., Chimana, H. and Sinsungwe, H., 1997. Status of Salmonella Gallinarum-Pullorum infections in poultry in Zambia. Avian Dis., 41,490-495. 
Snoeyenbos, G. H., 1978. Pullorum disease. In: Hofstad, M.S., Calnek, Helmboldt, C.F., Reid, W.M. and Yoder, H.W. (Eds): Diseases of Poultry $7^{\text {th }}$ edn. lowa State University Press, Ames, pp. 80-100.

Snoeyenbos, G.H., 1991. Pullorum disease. In: Calnek, B.W., Barnes, H.J., Beard, C.W., Reid, W.M. and Yoder, H.W., Jr. (Eds): Diseases of Poultry $9^{\text {th }}$ edn. lowa State University Press, Ames, pp. 73-86.

Williams, J. E., 1978. Introduction, Avian salmonellosis. In: Hofstad, M.S., Calnek, Helmboldt, C.F., Reid, W.M. and Yoder, H.W. (Eds): Diseases of Poultry $7^{\text {th }}$ edn. lowa State University Press, Ames, pp 79-80.

World Bank, 2008. The World Bank Group, World Development Indicators, September 2008. 